\title{
Techno-Economic Assessment of Distribution Network Reliability Services from Microgrids
}

DOI:

10.1109/ISGTEurope.2017.8260323

\section{Document Version}

Accepted author manuscript

Link to publication record in Manchester Research Explorer

\section{Citation for published version (APA):}

Martinez Cesena, E. A., Good, N., \& Mancarella, P. (2018). Techno-Economic Assessment of Distribution Network Reliability Services from Microgrids. In Innovative Smart Grid Technologies

https://doi.org/10.1109/ISGTEurope.2017.8260323

\section{Published in:}

Innovative Smart Grid Technologies

\section{Citing this paper}

Please note that where the full-text provided on Manchester Research Explorer is the Author Accepted Manuscript or Proof version this may differ from the final Published version. If citing, it is advised that you check and use the publisher's definitive version.

\section{General rights}

Copyright and moral rights for the publications made accessible in the Research Explorer are retained by the authors and/or other copyright owners and it is a condition of accessing publications that users recognise and abide by the legal requirements associated with these rights.

\section{Takedown policy}

If you believe that this document breaches copyright please refer to the University of Manchester's Takedown Procedures [http://man.ac.uk/04Y6Bo] or contact uml.scholarlycommunications@manchester.ac.uk providing relevant details, so we can investigate your claim.

\section{OPEN ACCESS}




\title{
Techno-Economic Assessment of Distribution Network Reliability Services from Microgrids
}

\author{
E. A. Martínez Ceseña ${ }^{1}$, N. Good ${ }^{1}$, and P. Mancarella ${ }^{1,2}$ \\ ${ }^{1}$ School of Electrical and Electronic Engineering, The University of Manchester, Manchester, UK \\ ${ }^{2}$ Department of Electrical and Electronic Engineering, University of Melbourne, Melbourne, Australia \\ \{Eduardo.MartinezCesena, Nicholas.Good, P.Mancarella\}@manchester.ac.uk
}

\begin{abstract}
This paper proposes a new techno-economic framework for the optimisation of Microgrid (MG) operation considering energy and reserve services, as well as a novel distribution network reliability service. The price signals required to incentivise reliability services are formulated based on the potential of MGs to improve reliability levels. This potential is quantified based on sequential Monte Carlo simulations and economic values assigned to reliability according to existing UK regulation. The results, based on pragmatic MG data and a real distribution network, highlight strong synergies between reliability services, and energy and reserve services. These synergies allow MGs to provide distribution network reliability support without significantly changing their normal behaviour or compromising their capabilities to provide other services.
\end{abstract}

Index Terms-Distribution networks, Microgrid, Monte Carlo simulation, Multiple services, Transactive energy.

\section{NOMENCLATURE}

Indices

$b \quad$ index of buildings, 1 to $N_{b}$

$i \quad$ index of settlement periods, 1 to $N_{i}$

$s \quad$ index of scenarios, 1 to $N_{s}$

Parameters

M arbitrarily large number

Resource

$B^{\min } / B^{\max } \quad$ battery energy $\min / \max$

$P^{\text {BESmin } \quad \text { batter power (min) }}$

$P^{\text {BESmax }} \quad$ batter power (max)

$\varphi \quad$ Battery round-trip efficiency

$(\mathrm{kWh})$

Demand/generation

$E_{s, i, b}^{\text {load }} \quad$ electricity load

$E_{s, i}^{\text {solar }} \quad$ solar electricity generation

Price profiles and parameters

$\lambda_{s, i}^{-} / \lambda_{s, i}^{+} \quad$ day-ahead electricity price

$(£ / \mathrm{kWh})$

$\mu_{s, i}^{-} \quad$ imbalance electricity import price

$\mu_{s, i}^{+} \quad$ imbalance electricity export price

$(£ / \mathrm{kWh})$

$(£ / \mathrm{kWh})$

$\pi_{i} \quad$ reserve availability price

$\beta_{s, i} \quad$ reliability service price

$\phi \quad$ reliability service indicator

$(£ / \mathrm{kW} / \mathrm{h})$

(£/kW/h)

(binary)
Rcall $^{\max } \quad \max$ length of reserve call

Relcall $^{\max }$

max length of reliability event

$\omega_{i}$ reserve window indicator

(binary)

Time-band length

$t \quad$ length of time step

Variables

$B_{S, i} \quad$ battery energy

$P_{s, i}^{B E S+} / P_{s, i}^{B E S-} \quad$ battery export/import power

$y_{s, i} / z_{s, i}$

binary variables

$(\mathrm{kW})$

$R_{s, i}^{r e s}$

reserve

(binary)

$\operatorname{Rel}_{s, i}$

reliability service capacity

$R(m)^{r e s}$

microgrid reserve

$(\mathrm{kW})$

$M_{s, i}^{-} / M_{s, i}^{+}$

market energy import/export

$(\mathrm{kWh})$

$I_{s, i}^{-} / I_{s, i}^{+}$

imbalance energy import/export

\section{INTRODUCTION}

The constant modernisation of the energy networks and the integration of distributed energy resources, such as Battery Energy Storage (BES) and solar Photovoltaic (PV) panels, are providing new opportunities for active demand side participation on the operation of energy systems [1]. As a result, new concepts such as Microgrids (MGs) are emerging as a means to coordinate the use of smart technologies and distributed energy resources to provide a wide range of services throughout the value chain during normal and emergency conditions. For example, MGs can use their resources to trade energy and reserve services in different energy markets during normal conditions [2]. Similarly, during emergency conditions when a section of the distribution network is disconnected due to a contingency, MGs can operate as islands to supply internal end-users. In addition, subject to the availability of relevant commercial agreements, distribution network automation technologies and spare generation capacity, the MGs could provide reliability services by reconnecting to the network and restore supply to external end-users in the vicinity [3].

The attractiveness of different services provided by smart community-level systems such as MGs has been explored in literature from technical and network level perspectives [1], [3]-[5]. The capability of MGs to increase the reliability levels 
experienced by end-users within the MGs has been widely explored in literature [6], [7]. In addition, research has emerged on the technical feasibility of MG applications to improve the reliability of the wider distribution network [7]. These studies explore the potential of network segmentation [8], [9] and MG collaborative behaviour [10], [11] to maintain end-user supply or expedite end-user restoration after contingencies occur (or extreme weather events in a resilience context). These works highlight the attractiveness of reliability services for the network; however, it is still unclear if there is a business case for MGs to pursue these services, particularly as the relevant flexibility and energy resources could be used to pursue other services (e.g., energy arbitrage, market balancing, etc.) [12]. To understand the viability of providing a reliability services whilst also taking part in other markets, the value of the reliability service must be quantified, transformed into a price signal, and considered in a optimisation with other relevant price signals, following transactive energy principles [13]. This exercise will reveal the value of the reliability service for the MG, and the conflicts or synergies between services.

To this end, this paper proposes a new techno-economic framework for the optimisation of MG operation in light of different services, including distribution network reliability support. The main contribution of this work is the consideration of a reliability services, using the value of MG export capability to define a reliability service price $\left(£ / \mathrm{kW}_{\text {export }}\right.$ capability), which can motivate MG BES to position itself to maximise revenue from this service. This means maintaining footroom to ensure electricity supply to the MG during a reliability event. This behaviour is similar to the behaviour motivated by provision of a low frequency reserve service [14]. However, for the reliability service the resource is the MG maximum available electricity export which can be maintained over the maximum reliability event, whereas for the reserve service it is the maximum MG electricity consumption reduction (compared to the scheduled operation) that can be maintained over the maximum reserve call duration. More detail is given in the problem formulation below. The formulation is demonstrated on a MG made up of 50 residential buildings, with PV and BES.

\section{PROBLEM FORMULATION}

This section presents a new techno-economic MG operation model, which has been built by extending mathematical programming MG/district operation models [14], [15] to also consider reliability services provided by MGs [4]. More specifically, the operation model identifies the optimal behaviour of the MG, including spare capacity that can be used to provide reliability services at different times (e.g., every half an hour period during representative days in each season). The impacts on the distribution network's reliability levels are then estimated based on sequential Monte Carlo simulations, and dynamic reliability prices are produced. The price signals are used to inform the operation model, which may recommend changing the operation of the MG to maximise benefits from reliability services. Further details on the reliability assessment and operation models are presented below.

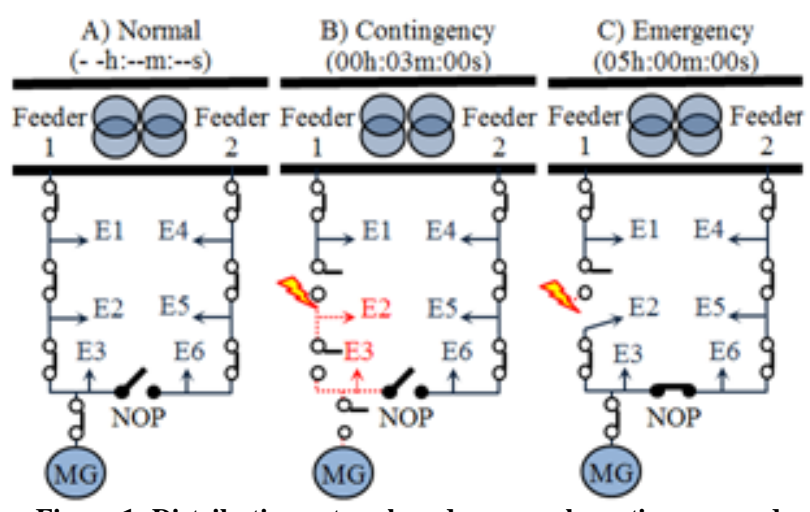

Figure 1: Distribution network under normal, contingency and emergency conditions.

\section{A. Reliability assessment}

MG can offer attractive reliability services to internal enduser and, subject to sufficient spare capacity, also to external end-users connected in the vicinity of the MG. The reliability levels experienced by internal end-users is based on the probability of the MG to successfully transition into an island and possess enough generation capacity to meet internal demand [8]. As MGs may be oversized for economic reasons [16], there is high potential for MGs to provide reliability support to the distribution networks. However, understanding the relevant reliability implications is not trivial, and requires explicit modelling of network operations when facing contingencies (see Figure 1), as well as the required operation of MGs to provide reliability support during those conditions.

\section{1) Distribution network operation practices}

Based on current UK practices, under normal operation conditions, groups of two or more high voltage distribution feeders (i.e., $6.6 \mathrm{kV}$ or $11 \mathrm{kV}$ ) are configured as open rings that are interconnected through Normally Open Points (NOPs) as shown in Figure 1A. If a contingency occurs, the protections devices generally isolate the contingency within 3 minutes (see Figure 1B). This may allow automatic reconnection of some end-users (i.e., E1) while other are isolated alongside the contingency (i.e., E2) or islanded from the network (i.e., E3 and the MG). Due to the open ring configuration, it is possible to (manually) operate the NOP to restore additional customers (i.e., E3 and the MG), which takes roughly an hour, whereas a crew would be sent to restore service to the rest of the end-users (i.e., E2), which takes roughly 5 hours. At this stage, the fault would be manually isolated, and the affected customers would be resupplied by connecting them to the network (see Figure 1C) or to a mobile generator.

\section{2) $M G$ reliability services}

Assuming that the proper agreements and automation infrastructure are in place, MGs could be in a position to provide reliability services by using their spare generation capacity to expedite customer restoration. As shown in Figure 2, the potential of MGs to provide reliability services is influenced by both the location of the contingency and the 
conditions of the network (e.g., contingency or emergency). That is, MG can provide short-term (for roughly an hour) reliability services for end-users that were disconnected from their feeder, but have access to other feeders through the NOP (see Figure 2A). In addition, more demanding reliability services where the MG would have to supply external endusers for several hours (while mobile generators are installed or the fault is cleared) would be required for end-users that become islanded from all feeders (see Figure 2B).

\section{3) Reliability indices and prices}

Based on existing UK regulations, distribution network reliability is evaluated in terms of Customer Interruptions (CI) and Customer Minutes Lost (CML) for events lasting more than three minutes (i.e., shorter interruptions are neglected) [17]. In light of this, sequential Monte Carlo simulations are used to simulate annual $\mathrm{CI}$ and CML under baseline conditions where the MG either does not provide reliability support (i.e., Baseline) or provides the service as recommended by the operation model (the model is presented in the next section).

The simulation is based on random location of contingencies throughout time based on the failure rates of the system, demand profiles and the expected operation of the network during contingency and emergency conditions. The expected reliability benefits introduced by the MG are then calculated based on the CI and CML estimated with and without consideration of MG support. These reliability improvements change through time due to the natural variations of the demand profile and the MG resources available to provide reliability services. Accordingly, dynamic reliability prices can be produced by combining these variable $\mathrm{CI}$ and CML signals with the economic value assigned to reliability (e.g., taken from existing UK regulation).

\section{B. Techno-economic operation $M G$ model}

The techno-economic model presented here has been formulated to optimise the operation of $\mathrm{MG}$ in light of different services. More specifically, the model optimises the use of BES (also considering PV generation) to maximise economic benefits associated with importing electricity from the market, and selling reserve and reliability services.

\section{1) Objective function}

MGs, as considered in this work, aim to minimise costs for internal end-users by optimising their energy trades and provision of services. For this purpose, as denoted by (1), MGs buy and sell electricity at import/export prices in the electricity market $\left(\lambda_{s, i}^{-}, \lambda_{s, i}^{+}\right)$and through the imbalance and settlement process $\left(\mu_{s, i}^{-}, \mu_{s, i}^{+}\right)$. MG reserve is remunerated according to the availability price $\left(\pi_{i}\right)$ whilst MG reliability capacity $\left(\operatorname{Rel}(m)_{s, i}\right)$ is remunerated (if the service is active, indicated by the binary parameter $\phi$ ) according to the reliability price $\left(\beta_{s, i}\right)$.

$$
\begin{aligned}
& \operatorname{Min}\left\{\sum _ { s = 1 } ^ { N _ { s } } \left[p _ { s } \sum _ { i = 1 } ^ { N _ { i } } \left(\lambda_{s, i}^{-} \mathrm{M}_{s, i}^{-}-\lambda_{s, i}^{+} \mathrm{M}_{s, i}^{+}+\mu_{s, i}^{-} I_{s, i}^{-}-\right.\right.\right. \\
& \left.\left.\left.\mu_{s, i}^{+} I_{s, i}^{+}-\omega_{i} \pi_{i} R(m)^{r e s} t-\phi \beta_{s, i} \operatorname{Rel}(m)_{s, i} t\right)\right]\right\}
\end{aligned}
$$

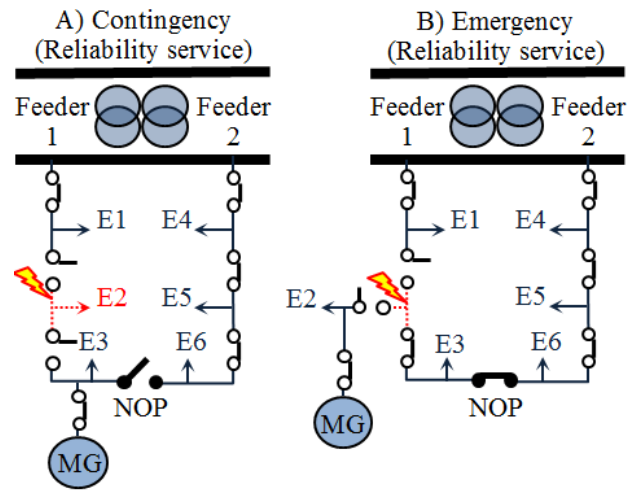

Figure 2: MG reliability support during contingency and emergency conditions.

\section{2) Battery Energy Storage}

BES energy level and charge/discharge constraints are set by (2)-(4). Constraints (5)-(6) ensure the battery does not charge and discharge at the same time, while (7) forces energy levels to be the same at the initial and last time-steps.

$$
\begin{aligned}
& B^{\text {min }} \leq B_{S, i} \leq B^{\text {max }} \\
& P^{\text {BESmin }} \leq P_{s, i}^{B E S+} \leq P^{\text {BESmax }} \\
& P^{B E S \sin } \leq P_{s, i}^{B E S-} \leq P^{B E S \max } \\
& P_{s, i}^{B E S+} \leq M z_{s, i} \\
& P_{s, i}^{B E S-} \leq M\left(1-z_{s, i}\right) \\
& B_{s, 0}=B_{S, N_{i}} \\
& \forall_{s \in\left[1: N_{S i}\right] ; i \in\left[0: N_{i}\right]} \\
& \forall_{s \in\left[1: N_{S i}\right] ; i \in\left[0: N_{i}\right]} \\
& \forall_{s \in\left[1: N_{S i}\right] ; i \in\left[0: N_{i}\right]} \\
& \forall_{s \in\left[1: N_{S i}\right] ; i \in\left[0: N_{i}\right]} \\
& \forall_{S \in\left[1: N_{S i}\right] ; i \in\left[0: N_{i}\right]} \\
& \forall_{s \in\left[1: N_{S i}\right]}
\end{aligned}
$$

It is worth noting that energy stored in the BES is a function of the previous energy level and the charging and discharging power, the latter adjusted to factor in the battery round-trip efficiency (8).

$B_{s, i+1}=B_{s, i}+\left(P_{s, i}^{B E S-}-P_{S, i}^{B E S+} / \varphi\right) t \quad \forall_{s \in\left[1: N_{s i}\right] ; i \in\left[0: N_{i}\right]}$

\section{3) Reserve and reliability services}

Reserve is modelled using the approach detailed in [14]. That is, reserve availability is limited by the maximum discharging power adjusted for the scheduled battery import and export, and the total energy in the battery, as denoted by (9) and (10), respectively.

$$
\begin{aligned}
& \begin{array}{c}
0 \leq R_{s, i}^{r e s} \leq P^{B E S \max }-P_{s, i}^{B E S+} \quad \forall_{S \in\left[1: N_{S i}\right] ; i \in\left[0: N_{i}\right]} \\
+P_{s, i}^{B E S-}
\end{array} \\
& R_{s, i}^{\text {res }} \leq B_{s, i} / \text { Rcall }^{\text {max }} \quad \forall_{s \in\left[1: N_{s i}\right] ; i \in\left[0: N_{i}\right]}
\end{aligned}
$$

The consideration of reliability services, which is a particular contribution of the presented formulation, is modelled with (11) and (12). The former limits the reliability capacity from the BES by the maximum export power, while the latter limits the reliability capacity available from the BES by the electricity stored.

$$
\begin{array}{cc}
0 \leq \operatorname{Rel}_{s, i} \leq P^{\text {BESmax }} & \forall_{s \in\left[1: N_{S i}\right] ; i \in\left[0: N_{i}\right]} \\
\text { Rel }_{s, i} \leq \frac{B_{s, i}}{\text { Relcall }^{\text {max }}} & \forall_{s \in\left[1: N_{S i}\right] ; i \in\left[0: N_{i}\right]}
\end{array}
$$

4) Energy, reserve and reliability balance

Energy consumption and generation at the locations within the MG must be aggregated and equated with the market 
energy purchases/sales. Equation (13) and (14) balance MG electricity production and consumption with market purchases and sales $\left(M_{s, i}^{-}, M_{s, i}^{+}\right)$, also considering purchases and sales in the imbalance settlement process $\left(I_{s, i}^{-}, I_{s, i}^{+}\right)$.

$$
\begin{array}{cc}
M_{s, i}^{-}-M_{s, i}^{+}+I_{s, i}^{-}-I_{s, i}^{+}=P_{s, i}^{B E S+} & \forall_{s \in\left[1: N_{s i}\right] ; i \in\left[0: N_{i}\right]} \\
-P_{s, i}^{B E S-}-E_{s, i}^{\text {solar }}+\sum_{b=1}^{N_{b}} E_{s, i, b}^{\text {load }} & \\
M_{s, i}^{-}, M_{s, i}^{+}, I_{s, i}^{-}, I_{s, i}^{+} \geq 0 & \forall_{s \in\left[1: N_{S i}\right] ; i \in\left[0: N_{i}\right]}
\end{array}
$$

Reserve balance is modelled based on UK practices for the STOR product [18]. That is, committed reserve must be the same across all windows. Equation (15) ensures this, whilst allowing for reserve to vary by scenario and time-step. This is beneficial for uncertain and diverse resources.

$\omega_{i} R(m)^{r e s}=\omega_{i} R_{s, i}^{r e s} \quad \forall_{s \in\left[1: N_{S i}\right] ; i \in\left[0: N_{i}\right]}$

BES reliability capacity and the MG electricity load is used to calculate the reliability service capacity (MG electricity load must be served first and hence reduces the reliability service capacity) (16). The form of (16), with a dummy variable $\left(\operatorname{Rel}(m)_{s, i}^{D}\right)$ allows the problem to remain viable even is electricity load exceed BES reliability capacity.

$$
\begin{array}{cc}
\operatorname{Rel}(m)_{s, i}-\operatorname{Rel}(m)_{s, i}^{D}= & \forall_{s \in\left[1: N_{s i}\right] ; i \in\left[0: N_{i}\right]} \\
\operatorname{Rel}_{s, i}-\frac{\sum_{b=1}^{N_{b}} E_{s, i, b}}{t}+\frac{E_{s, i}^{\text {solar }}}{t} & \\
\operatorname{Rel}(m)_{s, i} \leq M y_{s, i} & \forall_{s \in\left[1: N_{s i}\right] ; i \in\left[0: N_{i}\right]} \\
\operatorname{Rel}(m)_{s, i}^{D} \leq M\left(1-y_{s, i}\right) & \forall_{s \in\left[1: N_{s i}\right] ; i \in\left[0: N_{i}\right]}
\end{array}
$$

\section{CASE STUDY}

The proposed methodology is demonstrated through application to a MG that has been sized to supply fifty semidetached houses and is connected to a real UK distribution network, namely the Holme Road network (see Figure 3). The Holme Road network is an $11 \mathrm{kV}$ distribution network located in Preston and supplying 3700 customers (mostly residential and commercial). The network is currently $\mathrm{N}-1$ secure in light of dynamic rating criteria. That is, even if any single network segment becomes unavailable due to a contingency, the network can be reconfigured (using combinations of automated and manual operations) to supply all end-users without overloading any element of the network beyond emergency ratings (i.e., up to $20 \%$ overloads sustained by up to two hours in any $24 \mathrm{~h}$ period).

The MG under consideration was designed considering the installation of PV panels (20\% efficiency) and BES (90\% round-trip efficiency) as a means to supply internal energy demand at the lowest cost. As discussed in [19], the battery maximum import/export power (kW) is constrained to $60 \%$ of the battery capacity $(\mathrm{kWh})$. The study is run in a deterministic way, i.e., there is one scenario (Ns equals one, in each model run.

The internal energy profile of the MG is produced with diversified house profiles as described in [20]. The houses are heated by gas boilers and hence there is no heat related electricity consumption. Gas consumption is not considered

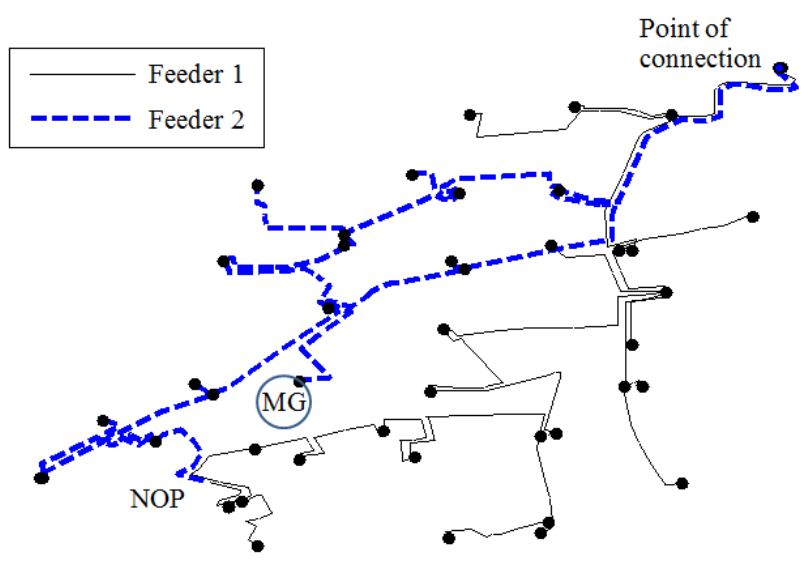

Figure 3: Holme Road 11kV distribution network.

in this work. An iterative algorithm is used to size both the PV and BES capacities. More specifically, PV and BES capacity is gradually increased while the associated Net Present Cost (NPC) is reduced. The NPC is calculated assuming a planning horizon of 15 years and a 5\% discount rate, as well as investment costs of $£ 953 / \mathrm{kW}$ and $£ 338 / \mathrm{kW}$ for PV and BES capacity, respectively [21]. The annual operational costs are produced with the proposed optimisation model presented in Section IIB, by running the model on seven representative days as in [12] (i.e., 15 peak days and weekdays and weekends for the winter, summer and shoulder seasons). The costs are calculated as a product of the electricity profiles and the wholesale-level prices, as discussed below. Based on this procedure, BES size is set at $78.58 \mathrm{kWh} / 47.15 \mathrm{~kW}$ and $\mathrm{PV}$ installation size at $30 \mathrm{~kW}$.

\section{A. Tests}

In this study, seven tests are considered based on different combinations of price signals, specifically Retail Energy (RE), Dynamic Energy (DE), reliability (Rel) and reserve (Res) prices (see Table I). In addition, a base test which only considers RE prices is used as a baseline for comparison. The export RE price is set at $£ 0.152 / \mathrm{kWh}_{\mathrm{e}}$ and the export at $£ 0.048 / \mathrm{kWh}_{\mathrm{e}}$ to reflect typical UK values. DE prices are set by utilising energy prices from the UK wholesale energy markets, variable use-of-system fees and tax elements. More detail on how these prices are constructed is given in [12]. For the Res prices and relevant windows are again set according to typical values for the UK short-term operating reserve product ( $£ 0.0045 / \mathrm{kW} / \mathrm{h}$, window definition varying by season [22]).

The dynamic and non-linear Rel service prices are defined based on the proposed model presented in Section IIA. More specifically, sequential Monte Carlo simulations considering over 17000 scenarios for contingencies throughout the year were used to simulate the reliability benefits attributed to the MG. For this purpose, a typical failure rate of $0.05 / \mathrm{km}$ was assumed, and the alternatives to close the NOP and place mobile generators as a means to restore supply to end-users (after contingencies occur) are assumed to take $1 \mathrm{~h}$ and $5 \mathrm{~h}$ in average, respectively. As considered in existing UK regulations, CI costs are set at $£ 15.44$ per interruption and CML costs are set at $£ 0.38$ per minute lost [17].

Utilised DE, Res and Rel prices for a typical summer weekday and a "peak" day (covering the 15 coldest days, on 
Table I: Test descriptions.

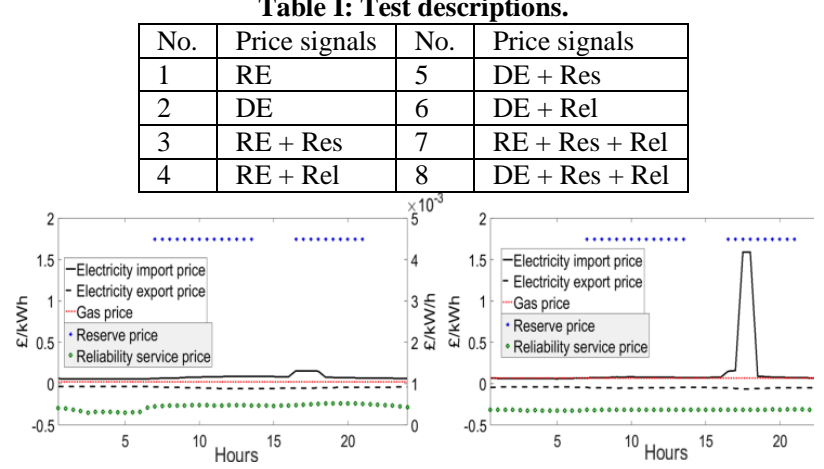

Figure 9: Summer weekday prices (left) and "Peak" day prices (right).

which transmission use-of-system fees are likely to be calculated[12]) are shown in Figure 9.

\section{RESULTS}

Focusing first on the impact of the reliability and other price signals the MG behaviour in selected cases is presented. Subsequently the revenue impacts of the tests are presented.

\section{A. MG behaviour}

Figure 4 shows the behaviour of the MG, for the summer weekday, given exposure to RE and Rel price signals. Given the large differential between import and export RE signals, the primary driver for the MG in this test is to maximise selfsupply. Indeed this motivation dominates the reliability service price signal. Nonetheless the reliability service capacity can be seen to rise when the net consumption of the MG (electricity load minus solar generation) is lower and as the BES State of Charge (SOC) increases, in line with (16) and (12). On the peak day, net consumption is greater due to increased electricity load and much reduced solar generation. Hence there is no motivation to use the BES to avoid export and the BES is kept full to maximize reliability service availability. However, this is still lower than in the summer weekday due to the greater net consumption.

Figure 6 shows the MG behaviour considering the DE, Res and Rel price signals, for the summer weekday. In this test the combination of reliability service and reserve price signals motivate the BES to be kept at near $100 \%$ SOC most of the day. In the afternoon there is some variation in the SOC as some demand is shifted from a higher price period at 1230 to a lower price one at 1530 . As opposed to Test 4 some export is scheduled. The cost of this is outweighed by the revenue from reserve and reliability services. During the peak day the BES SOC is generally maintained at a lower level to allow the BES to discharge to avoid electricity import during the afternoon high price period (recall that the BES SOC at the start of the day must match the BES SOC at the end of the day (7)).

The results above from Test 8 hint at an interesting property, i.e., the alignment of reserve and reliability service signals. This is demonstrated in Figure 8 which shows the MG export capacity in selected tests. As shown, the reserve price signals (present in Test 5) motivate the MG to have almost as much export capacity as the case which includes also the reliability

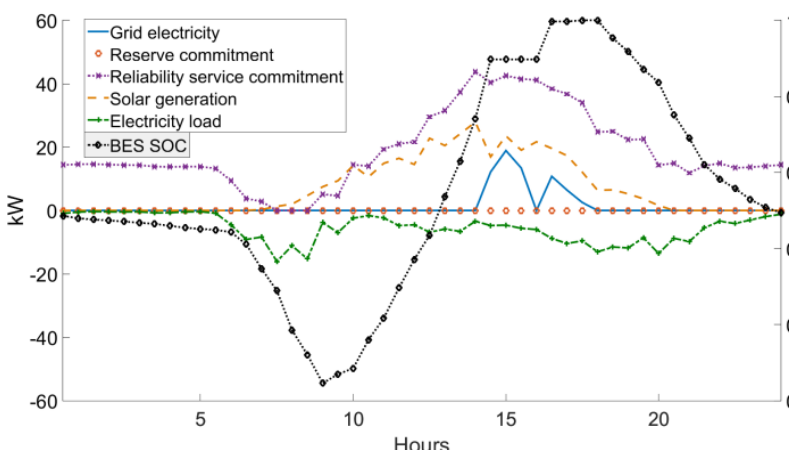

Figure 4: MG behaviour, Test 4, Season 1.

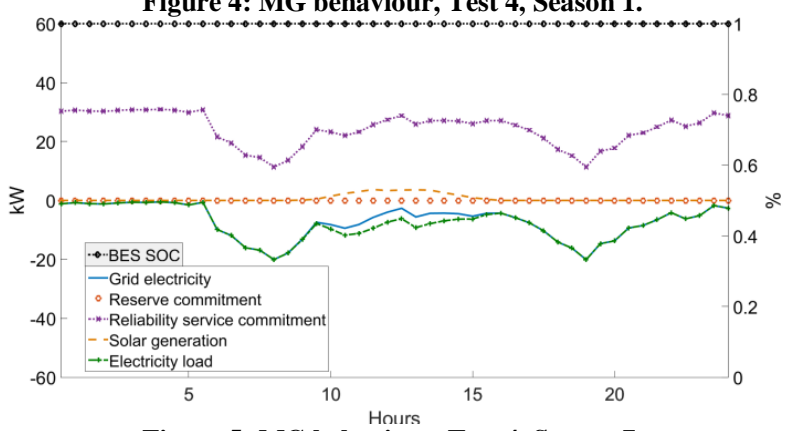

Figure 5: MG behaviour, Test 4, Season 7.

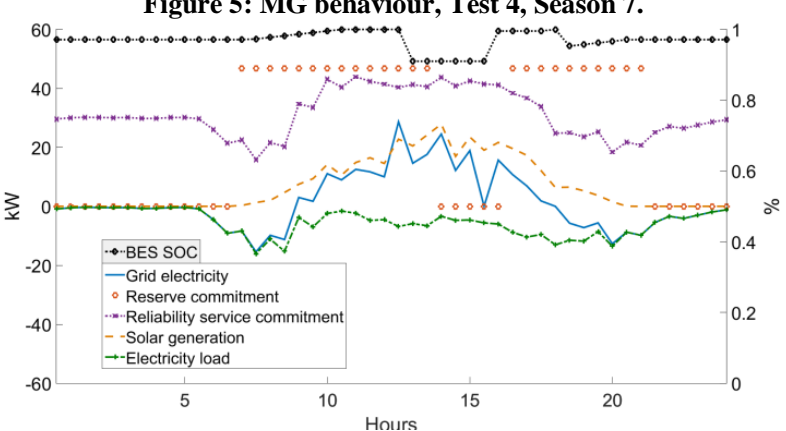

Figure 6: MG behaviour, Test 8, Season 1.

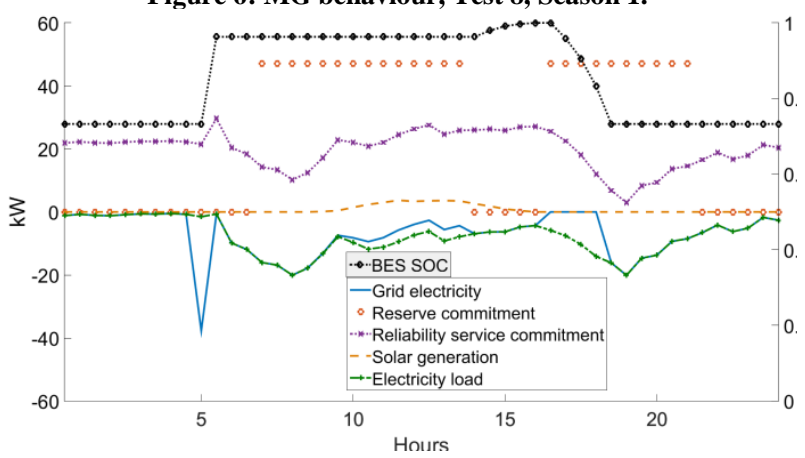

Figure 7: MG behaviour, Test 8, Season 7.

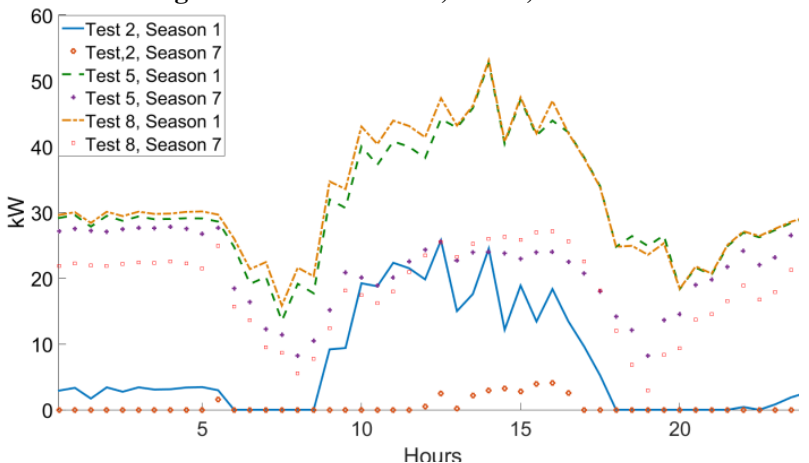

Figure 8: Comparison of MG export capacity, selected tests. 


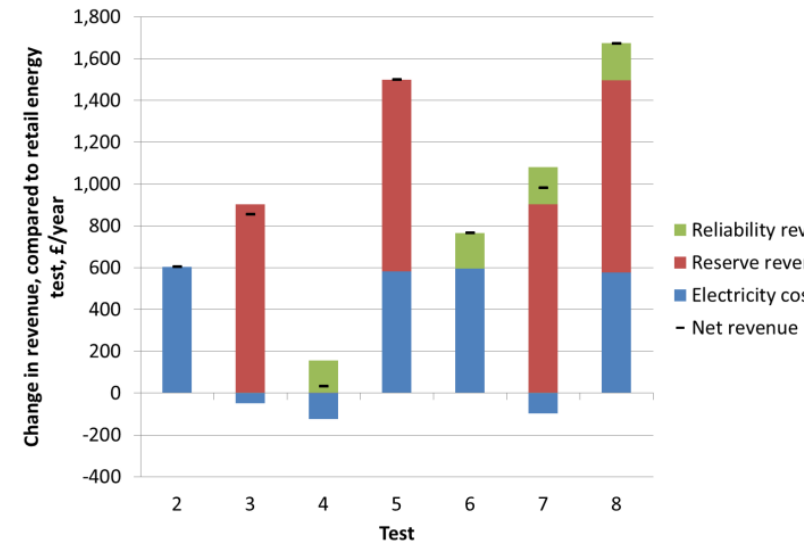

Figure 10: Test cash flow, compared to the retail energy test.

service price signals (Test 8), whilst DE signals alone (Test 2) motivate much less export capacity.

\section{B. MG revenue}

Figure 10 shows the change in cash flow for Tests 2-8 compared to Test 1 . The synergies between the considered services are demonstrated by the fact that, for Test 8 the total cash flow is approximately the same as the sum of the revenue in Tests 2-4.

\section{CONCLUSION}

This paper has proposed a new techno-economic framework to model the potential of MG to provide different services, particularly novel distribution network reliability support. The framework has been demonstrated on case studies based on pragmatic energy information and a real UK network.

The results, which explore the optimal operation of the MG when faced with different combinations of price signals, highlight two key points for MG with BES/PV resources. Firstly, MG behaviour is not affected significantly by the introduction of reliability-based price signals. Secondly, the low impact that dynamic price signals have on MG behaviour is mainly due to the strong synergies between the considered services. In other words, due to the nature of the reliability service, MG naturally operate in a manner that allows them to provide distribution network reliability support and, thus, no significant changes in their operation is required to further maximise benefits from the provision of reliability services.

\section{ACKNOWLEDGMENTS}

This work was developed with the contribution and within the scope of the LCNF Smart Street and EPSRC MY-STORE (EP/N001974/1) projects, as well as the H2020 SEAF projects (ref no. 696023) supported by the EC, which the authors would like to acknowledge.

\section{REFERENCES}

[1] E. A. Martínez Ceseña, N. Good, and P. Mancarella, "Electrical network capacity support from demand side response: Techno-economic assessment of potential business cases for small commercial and residential end-users," Energy Policy, vol. 82, pp. 222-232, 2015.

[2] N. Good, E. A. Martínez Ceseña, X. Liu, and P. Mancarella, "A Business Case Modelling Framework for Smart Multi-Energy Districts," in International Conference on Electricity Distribution, 2016, pp. 1-4.

[3] A. L. . Syrri, E. A. Martinez Ceseña, and P. Mancarella, "Contribution of Microgrids to distribution network reliability," in 2015 IEEE Eindhoven PowerTech, 2015, pp. 1-6.

[4] A. L. A. Syrri and P. Mancarella, "Reliability and risk assessment of post-contingency demand response in smart distribution networks," Sustain. Energy, Grids Networks, vol. 7, pp. 1-12, 2016.

[5] N. Good, E. A. Martinez Cesena, and P. Mancarella, “ $\square$ Mapping multiform flows in smart multi-energy districts to facilitate new business cases," Sustainable Places , 2014.

[6] S. Parhizi, H. Lotfi, A. Khodaei, and S. Bahramirad, "State of the art in research on microgrids: A review," IEEE Access, vol. 3. pp. 890-925, 2015.

[7] K. Schneider, F. Tuffner, M. Elizondo, C.-C. Liu, Y. Xu, and D. Ton, "Evaluating the Feasibility to Use Microgrids as a Resiliency Resource," IEEE Trans. Smart Grid, pp. 1-1, 2016.

[8] Y. M. Atwa and E. F. El-Saadany, "Reliability evaluation for distribution system with renewable distributed generation during islanded mode of operation," IEEE Trans. Power Syst., vol. 24, no. 2, pp. 572-581, 2009.

[9] S. Conti, S. A. Rizzo, E. F. El-Saadany, M. Essam, and Y. M. Atwa, "Reliability Assessment of Distribution Systems Considering Telecontrolled Switches and Microgrids," IEEE Trans. Power Syst., vol. 29, no. 2, pp. 598-607, 2014.

[10]Z. Wang and J. Wang, "Service Restoration Based On AMI and Networked Microgrids Under Extreme Weather Events," IET Gener. Transm. Distrib., 2016.

[11]M. Shahidehpour, xindong liu, Z. Li, and Y. Cao, "Microgrids for Enhancing the Power Grid Resilience in Extreme Conditions," IEEE Trans. Smart Grid, 2016.

[12] N. Good, E. A. Martínez Ceseña, L. Zhang, and P. Mancarella, “Technoeconomic and business case assessment of low carbon technologies in distributed multi-energy systems," Appl. Energy, vol. 167, pp. 158-172, 2016.

[13]N. Good and P. Martínez Ceseña, Eduardo A. Mancarella, "Ten Questions Concerning Smart Districts," Build. Environ., vol. In Press, 2017.

[14]N. Good and P. Mancarella, "Modelling and assessment of business cases for smart multi-energy districts," in PSCC, 2016.

[15]N. Good, E. Karangelos, A. Navarro-Espinosa, and P. Mancarella, "Optimization under Uncertainty of Thermal Storage-Based Flexible Demand Response with Quantification of Residential Users' Discomfort," IEEE Trans. Smart Grid, vol. 6, no. 5, 2015.

[16]E. A. Martínez Ceseña, T. Capuder, and P. Mancarella, "Flexible Distributed Multienergy Generation System Expansion Planning Under Uncertainty," IEEE Trans. Smart Grid, vol. In Press, 2015.

[17]E. A. Martínez Ceseña and P. Mancarella, "Practical recursive algorithms and flexible open-source applications for planning of smart distribution networks with Demand Response," Sustain. Energy, Grids Networks, vol. 7, pp. 104-116, 2016.

[18] O. Mégel, J. L. Mathieu, and G. Andersson, "Scheduling distributed energy storage units to provide multiple services under forecast error," Electr. Power Energy Syst., vol. 72, pp. 48-57, 2015.

[19]P. Papadopoulos, A. Laguna-Estopier, and I. Cooper, "Smarter Network Storage: SDRC 9.7 Successful Demonstrations of Storage Value Streams," 2016.

[20]N. Good, L. Zhang, A. Navarro-Espinosa, and P. Mancarella, "High resolution modelling of multi-energy domestic demand profiles," Appl. Energy, vol. 137, pp. 193-210, 2015.

[21]J. Carlsson, "ETRI 2014 - Energy Technology Reference Indicator projections for 2010-2050," 2014.

[22] National Grid, "STOR Market Info for TR24 - Appendix.” 2015. 